\title{
The effect of physical activity and indoor environment on preschool children's health
}

\author{
Maria Saridi ${ }^{1}$, Aikaterini Toska ${ }^{1}$, Dimitra Latsou ${ }^{2}$, Sofia Karakousi ${ }^{2}$, Eleni Albani ${ }^{1}$, Kyriakos Souliotis ${ }^{2}$, \\ and Pavlos Sarafis ${ }^{3}$
}

${ }^{1}$ Nursing Department, University of Thessaly, Lamia, Greece

${ }^{2}$ Department of Social and Educational Policy, University of Peloponnese, Greece.

${ }^{3}$ Nursing Department School of Health Science Cyprus University of Technology, Cyprus.

Magna Scientia Advanced Research and Reviews, 2021, 01(02), 045-055

Publication history: Received on 08 January 2021; revised on 10 February 202201; accepted on 12 February 2021

Article DOI: https://doi.org/10.30574/msarr.2021.1.2.0011

\begin{abstract}
Aim: The aim of the study was to investigate the effect of physical activity and indoor environment on preschool children's health.

Subject and Methods: The final sample comprised 126 parents of children of preschool age. An anonymous questionnaire was used in order to investigate the impact of indoor air pollution on the children's health. Data analysis was performed by using descriptive statistics and cross-tabulations with the SPSS 22.0.

Results: The majority of the parents were female (87.3\%) at an average age of 31-40 years (73\%). Regarding the children, there were an almost equal number of boys and girls and their age ranged between 3 and 6 years old. The children had not shown any signs of emotional or behavioural problems or other issues regarding regular physical functions and they hadn't shown any problems regarding recreational activities and interaction with friends (90.5\%). Cough is a frequent symptom in the case of a common cold (85.7\%). There were no statistically significant differences in the parents' responses as far as their children's health dimensions, concerning the availability of an air conditioner at home, the existence of pets and smoking habits in the family environment.
\end{abstract}

Conclusions: Improving air quality is an extremely complicated issue, since pollutants may be created both indoors and outdoors, which makes it very difficult to decrease them. Yet it still is definitely necessary, given the negative effects of pollution on human health, especially on the more vulnerable groups, such as children.

Keywords: Air Quality; Children's Health; Household Air Pollution; Indoor Environment.

\section{Introduction}

Indoor air pollution is the degradation of indoor air quality by harmful chemicals and other materials; it can be up to 10 times worse than outdoor air pollution. The indoor air pollutants have potential health effects [1]. Household air pollution was usually ignored, but in the last years the importance of air quality in indoor spaces has been repeatedly highlighted [2]. Conservative estimates have suggested that 1.5 to 2 million deaths internationally each year could be attributed to indoor air pollution. According to the World Health Organization (WHO), indoor air pollution was the cause of 4.3 million deaths in 2012, while 3.7 million deaths in the same year were attributed to atmospheric pollution. The

\footnotetext{
* Corresponding author: Aikaterini Toska; Email: ktoska07@yahoo.gr

Department of Nursing, University of Thessaly, Lamia, Greece.

Copyright (C) 2021 Author(s) retain the copyright of this article. This article is published under the terms of the Creative Commons Attribution Liscense 4.0.
} 
areas where indoor air pollution has been proven to be most deadly are South Asia, Central and West Africa (SubSaharan Africa) and Southeast Asia [3,4].

Indoor environment is the man-made environment within a building or setting built in order for people to reside, work, or spend considerable amounts of time for any other reason (houses and apartments, offices and shops, schools, hospitals, recreation facilities, mass transportation vehicles and facilities, etc). It is quite clear that the indoor environment is a subdivision of the environment in general, that carries its own importance since humans are born, live, procreate and die in man-made indoor environments and settings. It has been estimated that people may spend 50\%$100 \%$ of a time period indoors, while the main kind of indoor environment is one's home. Thus, household environment is very important since it may have adverse effects on human health [4-7].

Children are far more sensitive than adults to toxic chemicals in the environment. Proportional to body weight, children drink more water, eat more food, and breathe more air than adults. The physical attributes of children also cause them to live closer to the ground than adults do, which increases their exposure to toxins in dust, soil, and carpets [5].

The number of the rooms in the house is linked to indoor air pollution and child health because indoor air may be burdened by biomass fuels in a small house because of heating devices. Reliance on solid biomass fuel for cooking and heating purposes exposes many children of developing countries to high levels of indoor air pollution. [6].Young children are particularly at risk for high secondhand smoke exposure since they spend up to $90 \%$ of their time indoors and are more likely to be exposed to other members of the child's social network who smoke, i.e. extended family, child care workers and neighbors [7]. Regarding the significance of the number of the rooms of the house, it seems that uniformity of temperature is important because when the heating and cooling needs of the rooms within a single zone change at different rates, rooms that are served by a single thermostat may be at different temperatures [8]. Also, the main aim of ventilation in buildings is to create an indoor air quality more suitable for persons, and houses with many rooms may be benefited by this. Regarding children that share the same room, we can understand that separate rooms decrease the possibility of contamination, especially in pediatric and respiratory diseases $[7,9]$

Solid biomass fuel for cooking and heating, exposes many children to high levels of indoor air pollution and it is significantly associated with decline in lung function and higher prevalence of asthma in children [6]. Also since children spend nearly 20 hours per day indoors, indoor air quality became more important because of its potential effects on asthma [10]. This is mainly because children are more sensitive to environmental factors than adults, since they are still developing and growing, hence they are not yet able to cope with pollutants, and they also eat, drink and breath more in comparison to their body mass- so they are more vulnerable to environmental pollutants than adults [11].

Also, children's ability to detoxify differs from that of adults owing to their physiological status and the immaturity of their enzyme systems and clearance mechanisms [11].

Complete elimination of indoor air pollution is impossible, since in every indoor space -regardless of design, construction, maintenance and cleaning- there will always be even small amounts of pollutants present. A more realistic target would be to reduce the pollutants and keep them down to manageable and non-threatening levels. Humans, as creators and users of indoor spaces, have the technological means to improve indoor spaces and reduce dangerous pollutants, and the governments should also play an active role in that. Bioclimatic architecture is basically designing energy-saving buildings independent from oil and with less pollutants $[4,8,12,13]$.

We attempted to correlate the results with the children's daily physical activity, symptoms from the respiratory system, chronic or acute respiratory diseases, comorbidity and household environment. More specifically, some secondary targets of this study included registering the parents' beliefs on their children's health, highlighting signs of health problems caused by household pollution, and pinpointing sources of indoor air pollution.

\section{Material and methods}

The purpose of the present study was to investigate the effect of physical activity and the household environment on preschool children's health. Also we investigated the relationship between factors of indoor air pollution and health status of preschoolers (3-6 years old). A cross-sectional study was conducted among parents of 3 to 6 years old children, who visited public primary healthcare centers in the Prefecture of Corinth, Greece. Specifically, the Health Center of Kiato and the Health Center of Nemea were chosen to participate in the study, because these Health Centers are the two largest in Prefecture of Corinth, providing 24/7 services. The health center of Kiato serves 50,473 people and is located $22 \mathrm{~km}$ from the city of Corinth and the health center of Nemea serves 15.000 people and is located $41 \mathrm{~km}$ from the city of Corinth. 
A convenience sample of 150 parents was selected because there are no official records regarding children between 3 to 6 years old who live in those cities. The sample consisted of parents who visited the two Health Centers during morning clinic hours seeking healthcare services for their child. The exclusion criteria were: a) parents who visited the Health Centers in the afternoon or night (as an emergency), b) people who accompanied the child but did not belong to the family environment (grandmother, grandfather) or did not live with them, c) those who did not speak Greek. Parents were informed about the aim of the study and were asked if they agreed to participate. The study was carried out over a 4-month period (November 2013 to February 2014).

15 of the 150 parents refused to complete the questionnaire, while 9 questionnaires had mistaken and had to be excluded. The final sample comprised of 126 parents (response rate 84\%) of children of preschool age and each of the 126 adults came from a different household. Since the above-mentioned Health Centers were within the jurisdiction of the General Hospital of Corinth, the research protocol was submitted for approval to the Scientific Council of the Hospital. All participants granted informed consent by signing consent forms and strict anonymity was observed.

\subsection{Study instruments}

An anonymous questionnaire was used in order to investigate the impact of indoor air pollution on the health status of preschoolers. Primary data were collected by questionnaires and face to face interviews. About ten minutes on average were needed for each questionnaire to be completed.

The questionnaire included three sections. The first section was about the demographic characteristics of parents and their children such as gender, age, education level of parents and children, employment and family status. In the second section we used the Child Health Questionnaire - Parent Form [14,15], which has been standardized in Greek [16]. The questionnaire is self-completed, includes 23 questions (some with sub-questions) regarding children's health factors such as general health, physical activities, daily activities and physical pain. The answers of the questions were given either on a 5 point Likert scale (the highest score meaning better quality of life), or by dichotomous answers (yes / no). In the third section we selected some questions related to the impact of indoor air pollution on children's health from the "Parent's Questionnaire: Air Pollution and Pediatric Health Impact Study" by Dr. Crist Kevin (Associate Professor, School of Health Sciences, Ohio University). This questionnaire includes the presence of pain, cough, wheezing, respiratory and other disease, asthma and allergy. Regarding indoor air pollution, three questions were added about the use of air- conditioners, presence of pets and smoking habits in the house. In the last part of the questionnaire there are 12 questions that study the domestic environment and indoor air pollution). In particular, the location and type of the property, type of heating, presence of pets, use of air conditioners, indoor smoking, number of people living in the same home and number of rooms and bedrooms were investigated.

The questions the parents were called to answer were about physical and daily activities, as well as symptoms such as pain, coughing and wheezing for a period of four weeks before the study. The questions about respiratory and other diseases were about the last three years prior to the study.

\subsection{Statistical analysis}

Data analysis was performed by using descriptive statistics and cross tabulations with the SPSS 22.0. For the quantitative variables, means, and standard deviation were used. For the qualitative variables, nominal or ordinal, frequency distribution tables were used with percentages. For comparisons between dichotomous variables Pearson's chi-squared test was used and for quantitative variables between two groups the t- test was performed. Also, correlation analysis was conducted via Spearman's rho. The level of statistical significance was set to $\mathrm{p}<0.05$.

\section{Results}

The sample comprised 150 individuals, who met the eligibility criteria for the study. However, 15 of them refused to complete the questionnaire, while 9 questionnaires had mistaken and had to be excluded. The final sample consisted of 126 parents (response rate 84\%) of children of preschool age and each of the 126 adults represented a different household.

\subsection{Demographic characteristics of the sample}

The majority of the parents were women (87.3\%) aged on average 31-40 years (73\%). Most of the sample had full or part time jobs (64.3\%), and $93.7 \%$ of them were the children's biological parents. $92.9 \%$ were married and $42.1 \%$ of them were high school graduates. Regarding the children, there was an almost equal number of boys and girls and their 
age ranged between 3 and 6 years. The vast majority of the children (93.7\%) attend some kind of preschool education (Table 1).

Table 1 Parents' and Children's Demographics

\begin{tabular}{|c|c|c|}
\hline \multicolumn{3}{|l|}{ Children } \\
\hline & $\mathrm{N}$ & $\%$ \\
\hline \multicolumn{3}{|l|}{ Gender } \\
\hline Boys & 64 & 50.8 \\
\hline Girls & 62 & 49.2 \\
\hline \multicolumn{3}{|l|}{ First-born } \\
\hline Yes & 70 & 55.6 \\
\hline No & 56 & 44.4 \\
\hline \multicolumn{3}{|l|}{ Age (years) } \\
\hline 3 & 4 & 3.2 \\
\hline 4 & 31 & 24.6 \\
\hline 5 & 40 & 31.7 \\
\hline 6 & 51 & 40.5 \\
\hline \multicolumn{3}{|l|}{ Attending preschool education setting/program } \\
\hline Yes & 118 & 93.7 \\
\hline No & 8 & 6.3 \\
\hline \multicolumn{3}{|l|}{ Grade of education setting } \\
\hline Preschool & 28 & 22.2 \\
\hline Day care & 43 & 34.1 \\
\hline Kindergarten & 47 & 37.3 \\
\hline \multicolumn{3}{|l|}{ Parents } \\
\hline & $\mathrm{N}$ & $\%$ \\
\hline \multicolumn{3}{|l|}{ Gender } \\
\hline Male & 16 & 12.7 \\
\hline Female & 110 & 87.3 \\
\hline \multicolumn{3}{|l|}{ Age } \\
\hline $20-30$ & 14 & 11.1 \\
\hline $31-40$ & 92 & 73.0 \\
\hline $41-50$ & 17 & 13.5 \\
\hline $51-60$ & 3 & 2.4 \\
\hline \multicolumn{3}{|l|}{ Occupation } \\
\hline Unemployed (due to the child's health problems) & 1 & 0.8 \\
\hline Unemployed (other reasons) & 8 & 6.3 \\
\hline Scouting for a job & 12 & 9.5 \\
\hline Full or pat-time job & 81 & 64.3 \\
\hline Housekeeping & 24 & 19.0 \\
\hline
\end{tabular}




\begin{tabular}{|l|l|l|}
\hline Relation to the child & 118 & 93.7 \\
\hline Biological parent & 8 & 6.3 \\
\hline Legal guardian & \multicolumn{2}{l|}{} \\
\hline Educational level & 19 & 15.1 \\
\hline Elementary & 53 & 42.1 \\
\hline High-school graduate & 25 & 19.8 \\
\hline Higher Education & 25 & 23.0 \\
\hline University-level & 29 & \\
\hline Family status & \multicolumn{2}{l|}{} \\
\hline Single & 2 & 1.6 \\
\hline Married & 117 & 92.9 \\
\hline Divorced & 4 & 3.2 \\
\hline Separated & 3 & 2.4 \\
\hline
\end{tabular}

\subsection{Children's health and activities}

As far as the children's health was concerned, one out of two participants assessed it as excellent (49.2\%), 31.7\% described it as very good, $17.5 \%$ as good and only $1.6 \%$ of them thought their children's health was medium or poor. When parents asked if their children had limited their activities in the past four weeks due to health problems, $81 \%$ of the parents stated no limitations in intense physical activities, no limitations regarding medium energy level activities (81\%), and activities that consume high amounts of energy (75.4\%). Also, during the same time period, the children had not shown any signs of emotional or behavioural problems or other issues regarding regular physical functions. They hadn't shown any problems regarding recreational activities and interaction with friends (90.5\%), or other regular daily activities, at least not because of health-related problems (88.9\%). Regarding children' physical pain the majority of parents stated that their children never complained about physical pain (62.7\%), but $37.3 \%$ answered that there were complaints several times a week. Figure 1 shows the mean value of children's health and activities.

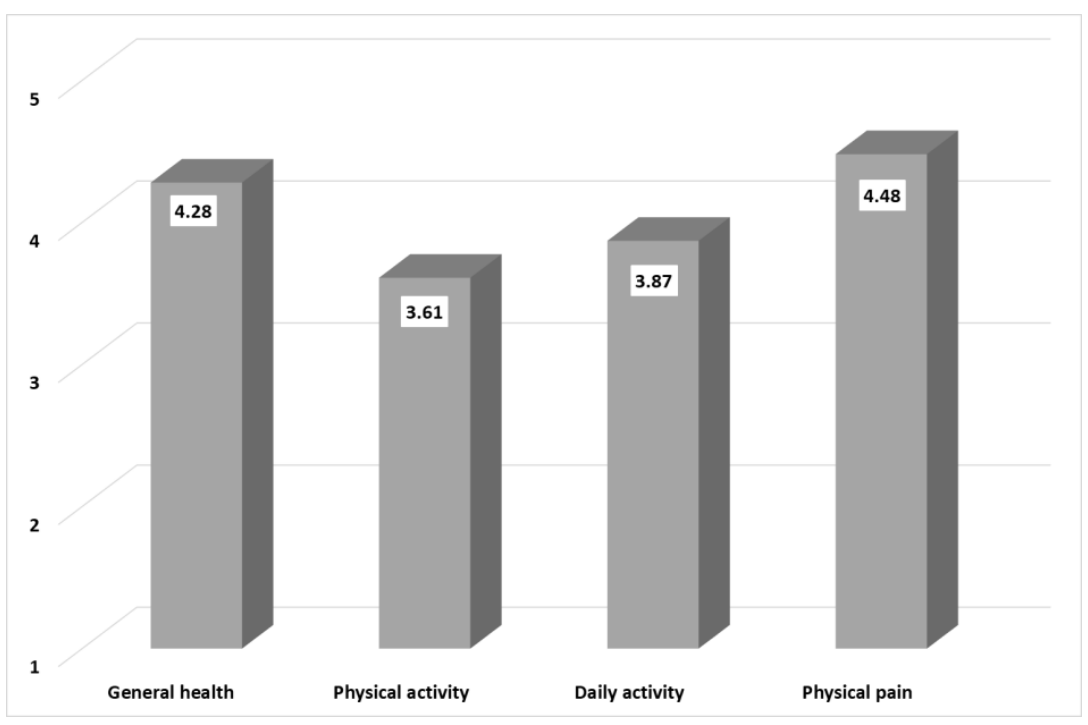

Figure 1 Children' health and activities

\subsection{Children's health problems}

Cough is a frequent symptom in case of a common cold (85.7\%), while it can be around even if the child has not caught a cold (18.3\%). In most of the cases, coughing is not a chronic symptom (84.7\%), and when it is, it has been present for one to five years (mean: 2.29 years). Wheezing had been present in $15.1 \%$ of the children. In most of the cases (78.9\%) there had been two or more episodes and pharmaceutical treatment or hospital admission had been required (94.7\%), 
while their breath returned back to normal between episodes (84.2\%), without any wheezing after intense play or other physical activities (84.2\%). According to the parents, in the past three years $26.2 \%$ of the children had to deal with some type of respiratory illness that caused them to limit their usual activities for at least 3 days. Most common conditions, apart from the common cold, had been bronchitis (31.7\%), bronchiolitis (23\%), laryngitis (22.2\%), rhinitis (21.4\%), asthmatic bronchitis (11.1\%) and pneumonia (1.6\%). On the other hand, no cases of measles, pertussis and cystic fibrosis were recorded.

Regarding the occurrence of asthma, most of the children (92.9\%) had no signs whatsoever, while when it did emerge in $7.1 \%$ of the children it started during their first year of life (mean 2.61 years), and disappeared at the age of three (mean 2.33 years). All the children that had asthma went under pharmaceutical or other treatment. $15.1 \%$ of the children showed some type of allergic reaction, and $14.3 \%$ of the parents said they had been informed by their pediatrician that their child had had some type of allergic reaction to dust and pollen, while $11.1 \%$ of the parents had been informed about allergic skin reactions to detergents or other chemicals.

\subsection{Indoor air pollution and other family traits}

As far as household characteristics were concerned, most of the families had four members (46\%), the house consisted of five (29.4\%) and four (27.8\%) rooms, and half of the children did not have to share their room with another person (48.4\%). Concerning types of heating systems, radiators were by far the most common one, either on their own (40.5\%) or combined with fireplaces $(22.2 \%)$. Electricity was the main power source $(91.3 \%)$ and food was cooked almost exclusively on electric stoves. In most of the cases there was an air-conditioning unit in the house (70.6\%), and there were no pets living in the house (73\%). The majority of the parents $(67.5 \%)$ said they didn't smoke in the house, while from those who did, $61 \%$ smoked even when the children were in the same room, and $70.7 \%$ allowed friends and visitors to smoke in the house too.

\subsection{Impact of indoor air pollution on children's health}

There were no statistically significant differences in parents' responses as far as their children's health level, compared to the availability of an air conditioner at home, the existence of pets and smoking habits indoors. An exception was observed in the dimension of daily activity and the existence of pets in the children's homes. According to parents' responses, children who have pets record a higher level of daily activities. Moreover, the existence of an air-conditioner is significantly linked to symptoms from the respiratory system, especially wheezing, respiratory diseases and asthma (Figure 2), albeit there was no correlation with coughing $(p=0.873)$ and allergies $(p=0.320)$. However, no correlation was found between the existence of an air-conditioner with coughing $(p=0.873)$ and allergies $(p=0.320)$. There wasn't also any difference among all of the above symptoms and the existence of pets or smoking. Finally, there was a significant difference in the parents' answers regarding indoor smoking with daily activities (mean 3.82, p=0.269) and physical pain (mean 4.63, p=0.112), (Table 2).

Table 2 Impact of DP on children' health dimensions

\begin{tabular}{|l|l|l|l|l|l|l|l|l|l|}
\hline \multirow{2}{*}{$\begin{array}{l}\text { Children's } \\
\text { health } \\
\text { dimensions }\end{array}$} & \multicolumn{4}{|l|}{ Use of air condition } & \multicolumn{3}{l|}{ Existence of pets in home } & \multicolumn{3}{l|}{$\begin{array}{l}\text { Smoking habits in the } \\
\text { family environment }\end{array}$} \\
\cline { 2 - 11 } & $Y E S$ & $N O$ & $P$ value & $Y E S$ & $N O$ & P value & $Y E S$ & NO & P value \\
\hline $\begin{array}{l}\text { General } \\
\text { health }\end{array}$ & 4.20 & 4.46 & 0.116 & 4.44 & 4,22 & 0.183 & 4.27 & 4.28 & 0.930 \\
\hline $\begin{array}{l}\text { Physical } \\
\text { activity }\end{array}$ & 3.66 & 3.49 & 0.254 & 3.71 & 3,58 & 0.414 & 3.54 & 3.64 & 0.514 \\
\hline Daily activity & 3.87 & 3.85 & 0.770 & 3.97 & 3,83 & 0.032 & 3.82 & 3.89 & 0.269 \\
\hline Physical pain & 4.49 & 4.46 & 0.809 & 4.38 & 4.52 & 0.347 & 4.63 & 4.41 & 0.112 \\
\hline
\end{tabular}




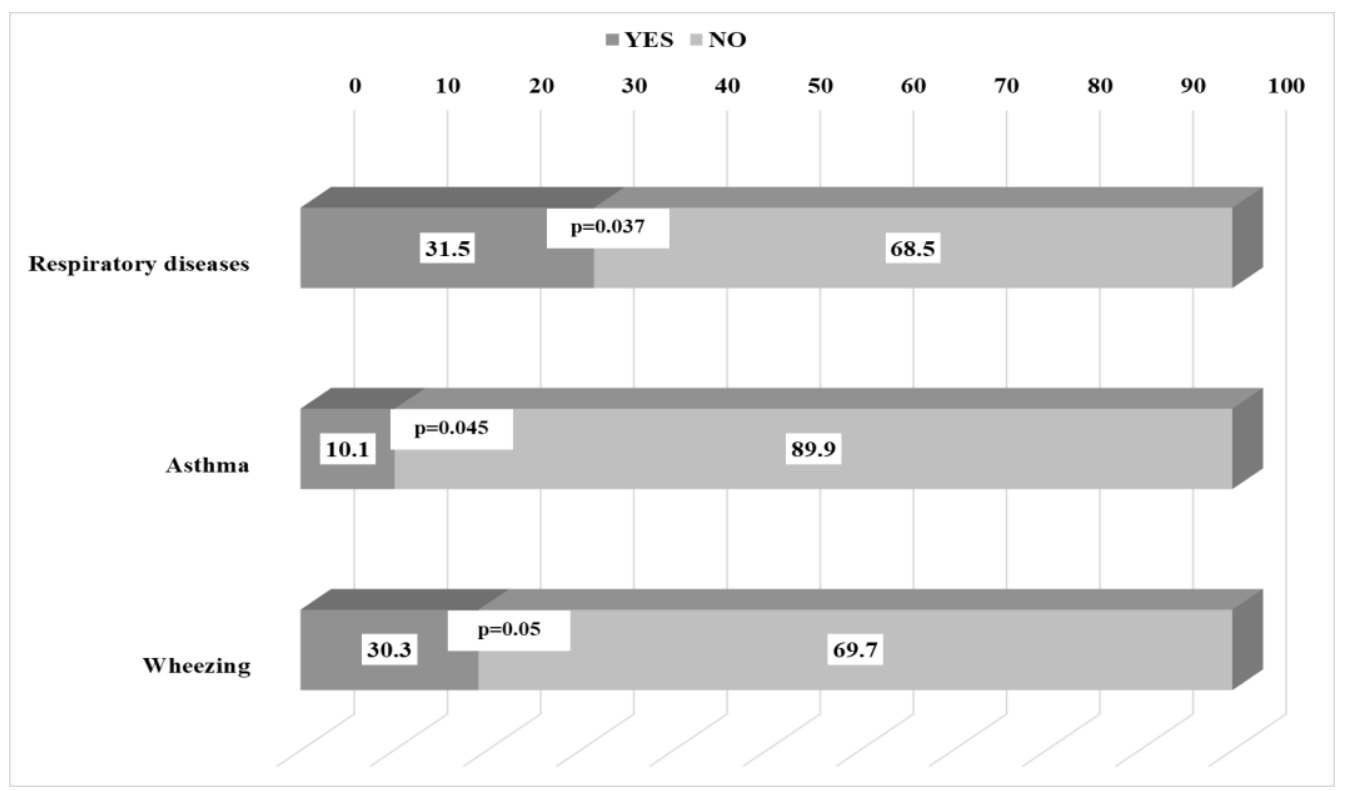

Figure 2 Comparison between availability of an A/C and symptoms from the respiratory system

\section{Discussion}

Environmental pollution has been widely acknowledged as a health-risk factor and a significant problem on a national and international level. Indoor air pollution may affect children's health, since they inhale larger quantities of air compared to their weight, and their organs are still developing $[17,18]$.

Our study aimed at investigating the relationship between Indoor air pollution factors and the health level of preschoolage children (3-6 years old). This study showed the parents' beliefs about their children's health, by investigating health problems due to indoor air pollution, and showing what are the main sources of indoor air pollution that could affect the children's health correlating them with their health level.

We found that one out of two parents thought their children's health to be excellent, and there were no serious limitations in everyday activities due to health problems, no emotional or behavioral problems, or issues related to limited physical functionality. Coughing is a common symptom in everyday life and is not always due to common cold, but wheezing shows up infrequently. Also, $26.2 \%$ of the children had had a respiratory illness in the past 3 years that limited them from their regular activities for at least 3 days.

Similar results were found in a study from Sweden, where preschoolers who were exposed to problematic indoor environment in their kindergartens had had higher rates of respiratory symptoms and common cold, whereas they had upper respiratory tract symptoms at least once during the school period and cough was a common symptom in the whole study population [19].

More asthma-related symptoms in children who live in public housing in Brazil show clearly the relationship between indoor environment quality and health [20].

Different types of ventilation methods (natural, A/C, and split A/C system) have different results; thus, natural ventilation methods used in day care units in Singapore lead to lower asthma, allergy and respiratory symptom rates compared to the other two methods [12].Data from north America and northern Europe have shown that insufficient ventilation and exposure to volatile organic compounds, as well as mold and allergens, increase the risk for respiratory symptoms, illnesses and allergies in children; consequently, asthma and "sick building syndrome" symptoms are common findings under these conditions [18-22].

The above mentioned data highlight the role the indoor environment can play regarding the emergence of breathing symptoms or problems. 
In our study only a small proportion of the children had asthma and slightly more had some type of allergy. A study from New York, where the children were submitted to skin prick tests and samples of air and dust were collected from their houses, showed high risk for the emergence of asthma [23].That study confirmed the correlation between asthma and problematic outdoor and indoor environment, as other relevant studies from Australia US, China and Bulgaria have also shown [24-27].

In our sample, the children lived in spacious and not over-crowded houses. The most common heating method was the radiator, and often a fireplace too, while the main source of power was electricity. A house in good shape can contribute to the inhabitants' good health, and the improvement of indoor environment can also have beneficial effects on health $[20,28]$. In our study, owning pets does not affect the children's general health. Yet relevant studies have pointed out a correlation between owing a pet and developing allergies or asthma, especially in children [29-31].

Another study showed that asthmatic children were more likely to be sensitized and had significantly higher indoor exposure to cat allergens than those who were only sensitized or only exposed to cat allergens [23]. On the other hand, owning a pet seems to have a positive effect on health, according not only to our findings but to those of other studies that have found that having pets can boost a kid's physical activity level $[23,32]$.

Another factor that could minimize allergies and other pet-related problems is to properly manage pets and paying attention to their hygiene [20]. Several studies have linked the house inhabitants' health level to the quality of the indoor environment $[28,33,34]$. Changing the indoor environment does not entail an immediate radical change in everything but it can lead to better health and well-being levels, especially for the children [35,36]. Of course, apart from getting rid of the allergens, other factors are equally important, namely having sufficient financial resources to realize those changes and making sure that all family members will cooperate $[37,38]$.

Dealing with allergens should begin from the bedroom by eliminating dust mites and fungi [31].]In addition, kitchens and bathrooms should be checked since they may have significant amounts of mold, high humidity and poor ventilation, followed by other areas like the basement, the garage or the garden [39].

$\mathrm{A} / \mathrm{C}$ is quite common and in this study it didn't prove to be a factor that could affect the children's health. As a matter of fact, other studies have suggested that A/C combined with proper ventilation may reduce indoor relative humidity below 50\% [20]. Studies suggest that homes with A/C are anticipated to have less outdoor to-indoor pollutant transport and smaller exposures to indoor pollutant levels. [20,40].

The majority of the participating parents used to smoke in the house and allowed visitors to smoke too. Similar study showed that almost half (46\%) of the households had more than one smoker in the home and their smoking locations were in their own bedroom, the kitchen or the living room (27\%) and over one-third of the children were exposed to second hand smoke [41]. Other studies have shown that indoor smoking can be linked to higher rates of childhood asthma [42-45]. Public smoking bans can significantly improve this situation [46,47].

On the other hand, there can't possibly be a law banning smoking in one's house, since this is linked to each family's own culture -or even the current social trends- but that situation could be gradually improved by health education campaigns $[3,4]$.On the contrary, if the parents smoke in the car with their children in it, their smoking could affect the child's health; hence, smoking in the car while children are in it, can be -and has been- legally banned in several countries $[48,49]$.

\subsection{Limitations}

The strong point of our study is the fact that in this survey a specific tool was used, which is an original attempt in Greece and internationally, since only recently the possible effects of indoor pollutants in preschoolers' health started to be investigated.

Despite the fact that every possible effort was made in every stage for the successful conduction of the study, there are some limitations that have to be mentioned.

Firstly, there is a limitation connected with the size of the study sample, since due to the small size, the results cannot be representative of the general population. Furthermore, the analysis of the indoor air pollution factors took place in a specific geographic area, whereas the choice of primary Healthcare Centers that were included in the study is a limitation in itself. 
Moreover, our study did not show an important burden of indoor air pollution, excluding indoor smoking. However, the fact that indoor air pollution was not measured with technological methods adds another limitation to our study.

From the above it seems that the results cannot be generalized to the general population. The expansion of this survey in a geographically wider and more representative sample, will give results with greater validity and reliability. Given that the district in which the study took place is a semi-urban and rural area, and the sample was living mainly in detached houses, it is necessary to plan a future study focusing on apartment buildings in cities.

\section{Conclusion}

This study attempted to address the issue of health and physical activity of preschool children, as their parents perceive it, in relation to indoor air pollution. The general health of the children and their physical functioning ranged from 'very good' to 'excellent'.

Respiratory diseases often occur in children of this age and can burden their health but do not affect their activities. From the indoor factors we studied, it was found that the use of air conditioners increases the probability of a respiratory disease, while there is no correlation between the presence of pets and respiratory diseases. However, the incidence of symptoms such as coughing and wheezing was more often in children whose parents smoke inside the house.

It is also important that the existence of pets within the house showed a higher level in all dimensions of children's health, while smoking inside the house showed a lower level in the general health of the children and their daily activity. Simple things like good ventilation, avoiding indoor smoking, proper cleaning and low humidity can be easily implemented and yield good results for the health of children and adults alike. A healthy and safe household environment is a key factor that can boost children's health.

\section{List of abbreviations}

WHO= World Health Organization

\section{Compliance with ethical standards}

\section{Disclosure of conflict of interest]}

There is not any conflict of interest for any of the authors

\section{Statement of informed consent}

Informed consent was obtained from all individual participants included in the study

\section{References}

[1] Kankaria A, Nongkynrih B, Gupta SK. Indoor air pollution in India: implications on health and its control. Indian J Community Med. 2014; 39(4):203-207

[2] Kampen V, MergetR,Baur X. Occupational airway sensitizers: an overview on the respective literature. Am J Ind Med. 2000; 38(2):164-218

[3] World Health Organization (WHO) Indoor Air Pollutants, Exposure and Health Effects Assessment. Copenhagen: World Health Organization Regional Office for Europe.2012. Available from: http://apps.who.int/iris/bitstream/10665/107300/1/euro series 78.pdf. Accessed 07 September 2017

[4] World Health Organization (WHO) Indoor Air Quality Research. Copenhagen: World Health Organization Regional Office for $\quad$ Europe.2014. Available from: http://www.euro.who.int/_data/assets/pdf_file/0005/74732/E71922.pdf Accessed 10 September 2017

[5] Avdalovic M, Putney L,Tyler $\mathrm{N}$ et al. In utero and postnatal exposure to environmental tobacco smoke (ETS) alters alveolar and respiratory bronchiole (RB) growth and development in infant monkeys. Toxicol Pathol. 2009; 37(2):256-263 
[6] Padhi BK, Padhy PK Domestic fuels, indoor air pollution, and children's health. Ann N Y Acad Sci .2008; 1140:209217

[7] Klepeis NE, Nelson WC, Ott W et al. (The National Human Activity Pattern Survey (NHAPS): A resource for assessing exposure to environmental pollutants. Journal of Exposure Analysis and Environmental Epidemiology. 2001; 11(3):231-252

[8] EPA. United States Environmental Protection Agency. Introduction to Indoor Air Quality. 2008 Factors Affecting Indoor Air Quality. Available from:https://www.epa.gov/sites/production/files/201408/documents/sec_2.pdf. Accessed 28 April 2018

[9] Sundell J. On the history of indoor air quality and health.I ndoor Air. 2004; 14(7):51-58

[10] Schwab M, McDermott A, Spengler JD. Using longitudinal data to understand children's activity patterns in an exposure context: data from the Kanawha Country Health Study. Envion Health Perspect.1992; 18:173-89

[11] Ginsberg G, Hattis D, Miller R et al. Pediatric pharmacokinetic data: Implications for environmental risk assessment for children. Pediatrics. 2004;113(3):973-983

[12] Zuraimi M, Tham KW, Chew F T et al. The effect of ventilation strategies of childcare centres on indoor air quality and respiratory health of children in Singapore.Indoor Air. 2007; 17(4):317

[13] Sundell J, Levin H, Nazaroff WW et al. Commemorating 20 years of Indoor air. Ventilation rates and health: multidisciplinary review of the scientific literature. Indoor Air. 2011; 21(3):191-204

[14] Raat H, Botterweck A M, Landgraf J M, et a. IReliability and validity of the short form of the child health questionnaire for parents (CHQ-PF28) in large random school based and general population samples. J Epidemiol Community Health .2005; 59(1):75-82

[15] CHQ.Child Health Questionnaire Available from: https://www.healthactchq. com/survey/chq. 2016. Accessed 05 June 2017

[16] Rekleiti M, Souliotis, K, Kambas, N et al. Validity and reliability of a questionnaire about air pollution and its impact on preschoolers' health. Perioperative Nursing 2018;7(1)

[17] Mendell MJ, Health GA. Do indoor pollutants and thermal conditions in schools influence student performance? A critical review of the literature. Indoor Air. 2005; 15(1):27-52

[18] Mendell MJ. Indoor residential chemical emissions as risk factors for respiratory and allergic effects in children: a review. Indoor Air. 2007; 17(4):259-277

[19] Daisey JM, Angell WJ, Apte MG. Indoor air quality, ventilation and health symptoms in schools: an analysis of existing information. Indoor Air. 2003; 13(1):53-64

[20] Burgos S, Sigala F, Argueta L et al. Child health environment in the context of relocating of camp site families to social housing. Rev Chil Pediatr. 2015; 86 (3):152-160

[21] Bornehag CG, Sundell J, Hägerhed L. Association between ventilation rates in 390 Swedish homes and allergic symptoms in children. Indoor Air. 2005; 15(4):275-280

[22] Weber A, Fuchsa N, Kutzora S et al. Exploring the associations between parent-reported biological indoor environment and airway-related symptoms and allergic diseases in children.Int J Hyg Environ Health.2017; 220(8):1333-1339

[23] Lin S, Gomez MI, Hwang SA et al. Self-reported home environmental risk factors for childhood asthma: a crosssectional study of children in Buffalo. J Asthma. 2008; 45(4):325-332

[24] Palmer LJ, Valinsky I.J. Pikora T et al Environmental factors and asthma and allergy in schoolchildren from Western Australia. Eur Respir J.2000; 14(6):1351-1357

[25] Lanphear BP, Aligne CA, Auinger P et al Residential Exposures Associated With Asthma in US Children. Pediatrics. 2001; 107 (3):505-511.

[26] Wong G, Ko F, Hui D et al Factors associated with difference in prevalence of asthma in children from three cities in China: multicentre epidemiological survey. BMJ. 2004; 329(7464):486

[27] Naydenov K, Popov T, Mustakov T et al. The association of pet keeping at home with symptoms in airways, nose and skin among Bulgarian children. Pediat Allergy and Immunol. 2008; 19(8): 702 - 708 
[28] Somerville M, Mackenzie I, Owen P et al. Housing and health: does installing heating in their home improve the health of children with asthma? Public Health. 2000; 114(6):434-440

[29] Pyrhönen K, NäyhäS, Läärä E. Dog and cat exposure and respective pet allergy in early childhood. Pediatr Allergy Immunol. 2015; 26(3):247-255

[30] Nilsson OB, van Hage M, Gronlund H Mammalian-derived respiratory allergens - implications for diagnosis and therapy of individuals allergic to furry animals. Methods. 2014; 66(1):86-95

[31] Gautier C, Charpin D. Environmental triggers and avoidance in the management of asthma. Journal of Asthma and Allergy. 2017; 10:47-56.

[32] Christian H, Trapp G, Lauritsen C et al. Understanding the relationship between dog ownership and children's physical activity and sedentary behavior. Pediatr Obes. 2013; 8(5);392-403

[33] Thomson H, Petticrew M, Douglas M. Health impact assessment of housing improvements: incorporating research evidence. J Epidemiol Community Health 2003; 57(1):11-16

[34] Green G, Ormandy, D, Brazier J et al. Tolerant building: the impact of energy efficiency measures on living conditions and health status. In: Nicol F, Rudge J, (eds). Cutting the cost of cold. London: E \& FN Spon.2000

[35] Jacobs DE, Ahonen E, Dixon SL et al. Moving into green healthy housing. J Public Health Manag Pract. 2015; 21(4):345-54

[36] Roberts D, Pontin D. The health risks of incense use in the home: an underestimated source of indoor air pollution? Community Pract. 2016; 89(3):36-41

[37] Milligan KL, Matsui E, Sharma H. Asthma in Urban Children: Epidemiology, Environmental Risk Factors, and the Public Health Domain. Curr Allergy Asthma Rep. 2016; 16(4):33

[38] Harving H, Korsgaard J, Dahl R. Clinical efficacy of reduction in house-dust mite exposure in specially designed, mechanically ventilated 'healthy' homes. Allergy .1994; 49(10):866-870

[39] HUD. Department of Housing and Urban Development Office of Lead Hazard Control. National Survey of Lead and Allergens in Housing. Final Report. 2001; Volume I. Analysis of Lead Hazards. Available fromhttp://www.nchh.org/Portals/0/Contents/Article0312.pdf. Accessed15 November 2017

[40] Sarnat JA, Brown KW, Schwartz J, et al. Ambient gas concentrations and personal particulate matter exposures: implications for studying the health effects of particles. Epidemiology. 2005; 16(3):385-95

[41] Butz AM Household Smoking Behavior: Effects on Indoor Air Quality and Health of Urban Children with Asthma. Matern and Child Health J. 2011; 15(4):460-468

[42] Zheng ZL, Deng HY, Wu CP et al. Secondhand smoke exposure of children at home and prevalence of parental smoking following implementation of the new tobacco control law in Macao. Public Health. 2017; $144: 57-63$

[43] Vitoria PD, Machado JC, Ravara SB et al. Portuguese children's exposure to secondhand tobacco smoke in the family car. Gac Sanit. 2015;29(2):13-14

[44] Al-Sayed EM, Ibrahim KS. Second-hand tobacco smoke and children. Toxicol Ind Health. 2014;30 (7):635-644

[45] Mason K Burden of disease from second-hand smoke exposure in New Zealand. N Z Med J. 2016; 129(1432):1625

[46] Mackay D, Haw S, Ayres JG et al. Smoke-free legislation and hospitalizations for childhood asthma. N Engl J Med. $2010 ; 363(12): 1139-1145$

[47] Millett C, Lee JT, Laverty AA et al. Hospital admissions for childhood asthma after smoke-free legislation in England. Pediatrics. 2013; 131(2):495-501

[48] Montreuil A, Hanusaik N, Cantinotti M et al Social disparities in children's exposure to secondhand smoke in privately owned vehicles. Tob Control. 2016; 26(6):663-668

[49] Northcross AL, Trinh M. Kim J et al. Particulate mass and polycyclic aromatic hydrocarbons exposure from secondhand smoke in the back seat of a vehicle. Tob Control. 2014; 23(1):14-20 